\title{
Physiological, anthropometric parameters, and balance skill response of healthy bankers to fitness training
}

\author{
Abigail Oforiwaa Doku', Monday Omoniyi Moses ${ }^{1, *}$, Isaac Kwaku Acheampong', Isaac Gyamfi', Charles Agbavor ${ }^{3}$, \\ Lady Gwendoline Akwa', Francis Osei', Eric Junior Appiah', Isaac Azo Tiguridaane', Prince De-Gaulle Deku' \\ 'Department of Sports and Exercise Science, Faculty of Allied Health Sciences, College of Health Sciences, Kwame Nkrumah University of Science and Technology, Kumasi, \\ Ghana \\ ${ }^{2}$ Ghana Lifesaving and Diving Association, Kumasi, Ghana \\ ${ }^{3}$ Kumasi Center for Collaborative Research in Tropical Medicine, Kwame Nkrumah University of Science and Technology, Kumasi, Ghana
}

Sedentary lifestyle as a predisposing factor of chronic diseases like hypertension, diabetes, stroke and obesity is a common phenomenon in the banking job. Studies suggest that fitness training improves health of bankers but has not been established among Ghanaian bankers. This study examined the physiological, anthropometric parameters, and balance skill responses of relatively healthy bankers to fitness training. Twelve bankers aged 28 to 55 years ( $36.41 \pm 7.16$ years) in Kumasi completed a 6-month fitness training program (FTP) of 30-min gym workouts and 1-hr swimming per session. Physiological, anthropometric parameters, and balance skill variables assessments were conducted in three trials: pretraining, midtraining and post-FTP. FTP caused significant decrease in pre-post systolic blood pressure $(P=0.001)$, diastolic blood pressure $(P=0.000)$, heart rate $(P=0.006)$, waist circumference $(P=$
0.007), waist-to-hip ratio $(P=0.007)$, and bone density $(P=0.038)$. There was significance decrease in body mass index $(P=0.047)$ between preand midtraining status. Weight significantly decreased among the three trials $(P=0.017)$. Pre-post opened $(P=0.043)$ and closed $(P=0.015)$ eye balance skills increased significantly. Effects of FTP were significantly higher in female $(P<0.05)$. Participants who were at the stage 1 and 2 hypertensions pretraining became normotensive posttraining. Six months FTP has beneficial effects on the physiological, anthropometric parameters, and balance skill of relatively healthy bankers.

Keywords: Sedentary, Hypertension, Fitness, Bankers, Physiological parameter, Anthropometric parameter

\section{INTRODUCTION}

The nature of banking job predisposes bankers to the risk of musculoskeletal disorders where stereotyped movements of the arms, hands and fingers, and repetitive occupational tasks are required (Gallagher and Heberger, 2013). Bankers undergo varying levels of inactivity-related mental stress to reduce manual error possibilities and are thus prone to chronic diseases like hypertension (Ganesh and Deivanai Sundaram, 2014). Higher prevalence of hypertension has been reported among employees of such profession (Hedén et al., 2014).

Inactive lifestyles contribute to a host of chronic diseases- high blood pressure, hypertension, diabetes, stroke, metabolic syndrome and obesity, which account for $70 \%$ of death in the advance world (Sardarinia et al., 2016). The problem that lies with chronic diseases is that it cannot be cured completely. Moreover, its management requires lifelong medication with some life-style modifications (Whelton et al., 2002). Furthermore, study has shown that the most effective and cost efficient therapy for chronic diseases is prevention through active lifestyle (Whelton et al., 2002).

Increase in the rate of overweight and obesity among married, non-smoking and employed Ghanaian adults has been reiterated (Addo et al., 2015). Although studies have shown that chronic

\footnotetext{
${ }^{*}$ Corresponding author: Monday Omoniyi Moses

(iD) https://orcid.org/0000-0001-5785-9551

Department of Sports and Exercise Science, Faculty of Allied Health Sciences,

College of Health Sciences, Kwame Nkrumah University of Science and

Technology, Kumasi, Ghana

E-mail: mmomoniyi.chs@knust.edu.gh

Received: November 14, 2018 / Accepted: February 4, 2019
} 
diseases would reduce with regular fitness training (FT), there remain a high prevalence of physical inactivity (13\%) among Ghanaian bankers (Addo et al., 2015; Paoli and Bianco, 2015). Studies have reiterated the significance of FT to all professions (Zhu and Haegele, 2018). The nature of banking job specifically predisposes bankers to sedentary lifestyle. Adherent to FT would help bankers to maintain energy balance, reduce fat mass, increase muscle mass, increase resting metabolic rate, and have a positive weight-modulating effect even on states of inactivity (Seo et al., 2015).

Although, FT would reduce unhealthy nature of banking job-related blood pressure, heart rate (HR), body fat percentage, back pain, waist to hip ratio (WHR), body weight, skeletal muscle percentage, obesity and poor balance, bankers' participation in FT has often been ignored. Although studies on general population to show effectiveness of FT through physical activities and exercise have been well reported, FT to improve the physiological, anthropometric parameters, and balance skill of Ghanaian bankers is scarce.

Our study specifically determined the systolic blood pressure (SBP), diastolic blood pressure (DBP), HR; hip circumference, waist circumference, WHR, body water percentage, body fat percentage, muscle mass, bone density, weight and body mass index (BMI); and standing-on-one-leg with opened eyes and closed eyes responses to FT.

\section{MATERIALS AND METHODS}

\section{Study design and setting}

The study adopted a pre-posttest experimental research design, participants were taken through a 6-month FT program and assessed on three occasions (first day at training; pretraining assessment, middle of the training program; midtraining assessment and last day of the training program; posttraining assessment). The study was conducted at Golden Bean Hotel poolside and gym. Ethical clearance was obtained from the Committee of $\mathrm{Hu}-$ man Research, Publication and Ethical approval at the School of Medical Science, Kwame Nkrumah University of Science and Technology with reference number CHRPE/AP/571/17. All participants signed written informed consent form.

\section{Sampling technique}

Letter was initially sent to 15 banks within Kumasi metropolis to seek for interested bankers who would participate in the study. Only 12 whose mean age (standard deviation, SD) was $36.41 \pm$
7.17 years; mostly married $( \pm 10)$, females $( \pm 9)$ and mean $(\mathrm{SD})$ of the work experiences was $12.42 \pm 8.89$ years showed interest and enrolled initially. In the course of the FTP, due to disclosed personal reasons and work schedules, some participants dropped out. Hence 11 participants were assessed during the midtraining assessment and nine after the training. The convenience sample technique was used for the study. The study included (a) bankers with minimum of 5 years working experience; (b) nondiabetic, nonstroke, not living with any physical and psychological conditions; and (c) sedentary healthy bankers.

\section{Measurements}

Pre-post intervention data on the physiological parameters (SBP, DBP, and HR), anthropometric parameters (weight, waist circumference, hip circumference, waist-to-hip ratio, total body water percentage, total body fat percentage, bone density, skeletal muscle mass, and BMI), and balance skill parameter (opened-eye balance skill and closed-eye balance skill) were measured. Automatic blood pressure monitor, model: M2 Basic, HEM-7120-E (Omron Healthcare Co. Ltd., Kyoto, Japan) was used to measure blood pressures and pulse. The nonextensible and flexible tailors' or dressmaking measuring tapes TR-16W-60 and TR-16B-60 (The Perfect Measuring Tape Co., Toledo, OH, USA) was used to measure height, waist circumference and hip circumference. A Taylor Body fat analyzer, scale-5742 (Taylor Precision Products Inc., Las Cruces, NM, USA) was used to measure body weight, body fat percentage, body water percentage, skeletal muscle mass, and bone density.

A Casio fx-991 (Casio Computer Co. Ltd., Tokyo, Japan) ES natural display (2-way power) calculator was used to calculate the BMI of each participant and any other arithmetic. Stopwatch pro100 (Momentum St Moritz Watch Corp., Vancouver, Canada) was used to measure the time for the balance skills. Non-slippery-even floor; was used to access the balance skill of the bankers. The measured waist circumference and hip circumference of the participants was used to calculate their WHRs, using the formula: WHR = waist circumference/hip circumference.

Record of weights and heights were used to calculate BMIs with the formula: BMI = body weight $(\mathrm{kg}) /$ height $\left(\mathrm{m}^{2}\right)$. Data collection sheet (researcher's own construct) was used to collect the demographical detail (age, marital status, work experience, and number of children), physiological parameters (SBP, DBP, and $\mathrm{HR}$ ), anthropometric parameters (weight, waist circumference, hip circumference, WHR, total body water percentage, total body fat percentage, bone density, skeletal muscle mass, and BMI), and 
balance skill parameter (opened-eye balance skill and closed-eye balance skill) of the participants. A pretraining data on Monday was collected before the commencement of the FT program and kept as baseline data; after 3 months of the FT program, midtraining data was collected and on Saturday of the last week, post data collection was carried out.

\section{Intervention}

Three training sessions were organized per week for 6 months. Every training session started and ended with warm up and cool down respectively each lasting for $10 \mathrm{~min}$. The swimming lessons
( $60 \mathrm{~min}$ ) for the week was repeated in every session until the week ends but there were different gym work out (30 min before swimming session) for every session per week.

\section{Statistical analysis}

The primary data was analyzed with IBM SPSS Statistics ver. 23.0 (IBM Co., Armonk, NY, USA) and presented in accordance with the study objectives. The general linear model was used to obtain the effect of FT on the various parameters. Repeated measure (pairwise comparisons) was used to check the pretraining, midtraining and posttraining effect on all the parameters with

Table 1. Physiological, anthropometric parameters, and balance skill responses of healthy bankers to fitness training

\begin{tabular}{lcccc}
\hline Parameter & Pretraining & Midtraining & Posttraining & $P$-value \\
\hline Systolic blood pressure $(\mathrm{mmHg})$ & $118.36 \pm 10.10$ & $116.36 \pm 12.73$ & $109.44 \pm 9.94$ & $0.001^{*}$ \\
Diastolic blood pressure $(\mathrm{mmHg})$ & $83.36 \pm 5.61$ & $74.27 \pm 7.02$ & $72.00 \pm 6.13$ & $0.001^{*}$ \\
Heart rate $(\mathrm{bpm})$ & $84.67 \pm 8.52$ & $79.44 \pm 7.44$ & $68.78 \pm 5.89$ & $0.006^{*}$ \\
Weight $(\mathrm{kg})$ & $86.66 \pm 19.51$ & $76.62 \pm 17.06$ & $74.11 \pm 16.95$ & $0.017^{*}$ \\
Waist circumference $(\mathrm{cm})$ & $94.17 \pm 14.09$ & $89.56 \pm 11.71$ & $83.83 \pm 10.87$ & $0.007^{*}$ \\
Hip circumference $(\mathrm{cm})$ & $109.17 \pm 14.20$ & $105.83 \pm 11.96$ & $111.00 \pm 14.72$ & 0.738 \\
Waist-to-hip ratio & $0.86 \pm 0.07$ & $0.84 \pm 0.05$ & $0.76 \pm 0.009$ & $0.022^{*}$ \\
Body water $(\%)$ & $51.50 \pm 7.09$ & $51.66 \pm 6.53$ & $52.78 \pm 7.05$ & 0.448 \\
Body fat $(\%)$ & $27.39 \pm 9.69$ & $27.89 \pm 9.74$ & $26.37 \pm 9.44$ & $3.51 \pm 0.54$ \\
Bone density $(\mathrm{kg})$ & $3.29 \pm 0.61$ & $3.34 \pm 0.56$ & $24.99 \pm 6.93$ & 0.324 \\
Skeletal muscle mass $(\mathrm{kg})$ & $24.41 \pm 6.31$ & $24.83 \pm 7.68$ & $27.33 \pm 6.46$ & $0.014^{*}$ \\
Body mass index $\left(\mathrm{kg} / \mathrm{m}^{2}\right)$ & $31.04 \pm 6.69$ & $27.33 \pm 6.12$ & $87.58 \pm 73.18$ & 0.247 \\
Opened-eye balance time $(\mathrm{sec})$ & $27.54 \pm 20.62$ & $95.09 \pm 138.35$ & $22.88 \pm 14.74$ & $0.047^{*}$ \\
Closed-eye balance time $(\mathrm{sec})$ & $10.74 \pm 7.06$ & $9.52 \pm 7.54$ & $0.043^{*}$ & $0.015^{*}$ \\
\hline
\end{tabular}

Values are presented as mean \pm standard deviation.

${ }^{*} P<0.05$, significant difference.

Table 2. Pairwise comparisons of physiological, anthropometric parameters, and balance skills

\begin{tabular}{|c|c|c|c|c|c|}
\hline Parameter & (I) & (J) & Mean difference (I-J) & $P$-value & $95 \% \mathrm{Cl}$ \\
\hline \multirow[t]{2}{*}{ Systolic blood pressure (SBP) } & SBP3 & SBP1 & $10.556^{*}$ & 0.002 & 4.692-16.420 \\
\hline & & SBP2 & $9.222^{*}$ & 0.003 & $0.936-17.508$ \\
\hline \multirow[t]{2}{*}{ Diastolic blood pressure (DBP) } & DBP1 & DBP2 & $8.333^{*}$ & 0.002 & $1.442-15.225$ \\
\hline & & DBP3 & $12.667^{*}$ & 0.002 & 5.849-19.485 \\
\hline \multirow[t]{2}{*}{ Heart rate (HR) } & HR3 & HR1 & $15.889^{*}$ & 0.017 & $3.149-28.629$ \\
\hline & & HR2 & $10.667^{*}$ & 0.048 & $0.88-21.246$ \\
\hline \multirow[t]{2}{*}{ Waist circumference (WC) } & WC3 & WC1 & $10.333^{*}$ & 0.022 & $1.584-19.083$ \\
\hline & & WC2 & $5.722^{*}$ & 0.009 & $1.638-9.806$ \\
\hline Waist-to-hip ratio (WHR) & WHR2 & WHR3 & $0.790^{*}$ & 0.043 & $0.002-0.155$ \\
\hline Opened-eye balance time (OEBT) (sec) & OEBT1 & OEBT3 & $60.049^{*}$ & 0.043 & 2.249-117.849 \\
\hline \multirow[t]{2}{*}{ Closed-eye balance time (OEBT) (sec) } & CEBT1 & CEBT3 & $12.138^{*}$ & 0.045 & $0.278-23.998$ \\
\hline & & CEBT2 & $13.358^{*}$ & 0.010 & 3.596-23.119 \\
\hline
\end{tabular}

Based on estimated marginal means.

$\mathrm{Cl}$, confidence interval.

${ }^{*} P<0.05$, significant difference. ${ }^{\text {a) }}$ Adjustment for multiple comparisons: Bonferroni. 
bonferroni statistically significant adjustment where $P<0.05$. Descriptive statistics of mean and standard deviation was used for the participants' demographic variables.

\section{RESULTS}

Table 1 shows significance decline in SBP and DBP, HR, body weight, waist circumference, waist-to-hip ratio and BMI as well as increase in bone density and balance initial pre- and final posttest $(P<0.05)$. Specific direction of the significant differences among the three trails - pretraining (1), midtraining (2), and posttraining (3) in the measured variables presented in Table 2. Table 3 reveal that FT significantly enhanced reduction in body weight, SBP, DBP, HR, WHR, waist circumference and increased

Table 3. Physiological, anthropometric parameters, and balance skill responses of healthy male and female bankers to fitness training

\begin{tabular}{|c|c|c|c|c|c|}
\hline Parameter & Gender & Pretraining & Midtraining & Posttraining & $P$-value \\
\hline \multirow[t]{2}{*}{ Systolic blood pressure $(\mathrm{mmHg})$} & M & $123.67 \pm 9.87$ & $115.33 \pm 9.07$ & $110.67 \pm 10.07$ & 0.089 \\
\hline & $\mathrm{F}$ & $118.17 \pm 10.34$ & $120.33 \pm 14.91$ & $108.83 \pm 10.78$ & $0.008^{*}$ \\
\hline \multirow[t]{2}{*}{ Diastolic blood pressure $(\mathrm{mmHg})$} & M & $81.67 \pm 3.51$ & $73.33 \pm 2.08$ & $68.33 \pm 7.64$ & 0.056 \\
\hline & $\mathrm{F}$ & $86.17 \pm 5.53$ & $77.83 \pm 5.19$ & $73.83 \pm 4.96$ & $0.012^{*}$ \\
\hline \multirow[t]{2}{*}{ Heart rate (bpm) } & M & $85.67 \pm 8.96$ & $82.00 \pm 6.08$ & $71.67 \pm 2.88$ & 0.154 \\
\hline & $\mathrm{F}$ & $82.67 \pm 8.19^{*}$ & $78.00 \pm 13.44$ & $67.33 \pm 6.68$ & $0.036^{*}$ \\
\hline \multirow[t]{2}{*}{ Waist circumference $(\mathrm{cm})$} & M & $90.33 \pm 7.23$ & $85.33 \pm 7.57$ & $80.00 \pm 10.58$ & 0.222 \\
\hline & $\mathrm{F}$ & $93.39 \pm 14.11$ & $90.50 \pm 11.67$ & $85.75 \pm 11.44$ & $0.036^{*}$ \\
\hline \multirow[t]{2}{*}{ Hip circumference (cm) } & M & $100.67 \pm 7.51$ & $98.00 \pm 3.46$ & $98.67 \pm 5.13$ & 0.771 \\
\hline & $\mathrm{F}$ & $110.50 \pm 13.89$ & $109.69 \pm 11.24$ & $117.17 \pm 14.12$ & 0.643 \\
\hline \multirow[t]{2}{*}{ Waist-to-hip ratio } & $M$ & $0.90 \pm 0.10$ & $0.86 \pm 0.06$ & $0.81 \pm 0.11$ & 0.523 \\
\hline & $\mathrm{F}$ & $0.85 \pm 0.05$ & $0.83 \pm 0.05$ & $0.74 \pm 0.08$ & $0.006^{*}$ \\
\hline \multirow[t]{2}{*}{ Weight (kg) } & $M$ & $77.60 \pm 14.51$ & $75.97 \pm 12.87$ & $74.33 \pm 10.31$ & 0.317 \\
\hline & $\mathrm{F}$ & $85.13 \pm 19.74$ & $76.38 \pm 16.91$ & $74.00 \pm 20.42$ & $0.075^{*}$ \\
\hline \multirow[t]{2}{*}{ Body water (\%) } & M & $60.03 \pm 4.57$ & $59.93 \pm 3.91$ & $60.90 \pm 3.57$ & 0.368 \\
\hline & $\mathrm{F}$ & $47.50 \pm 2.25$ & $46.96 \pm 1.27$ & $48.72 \pm 3.89$ & 0.328 \\
\hline \multirow[t]{2}{*}{ Body fat (\%) } & $M$ & $16.80 \pm 8.57$ & $16.67 \pm 7.53$ & $16.23 \pm 7.51$ & 0.456 \\
\hline & $\mathrm{F}$ & $32.59 \pm 4.05$ & $33.43 \pm 3.39$ & $31.43 \pm 5.24$ & 0.485 \\
\hline \multirow[t]{2}{*}{ Bone density (kg) } & $M$ & $3.77 \pm 0.06$ & $3.80 \pm 0.10$ & $3.90 \pm 0.10$ & $0.057^{*}$ \\
\hline & $\mathrm{F}$ & $3.06 \pm 0.49$ & $3.20 \pm 0.50$ & $3.32 \pm 0.57$ & 0.136 \\
\hline \multirow[t]{2}{*}{ Skeletal muscle mass (kg) } & $M$ & $31.43 \pm 2.48$ & $33.70 \pm 3.72$ & $32.90 \pm 2.52$ & 0.396 \\
\hline & $\mathrm{F}$ & $20.98 \pm 3.49$ & $20.89 \pm 3.87$ & $21.03 \pm 4.23$ & 0.764 \\
\hline \multirow[t]{2}{*}{ Body mass index $\left(\mathrm{kg} / \mathrm{m}^{2}\right)$} & $M$ & $25.90 \pm 3.94$ & $24.87 \pm 2.65$ & $25.83 \pm 2.25$ & 0.955 \\
\hline & $\mathrm{F}$ & $34.07 \pm 7.13$ & $29.00 \pm 8.02$ & $28.08 \pm 7.92$ & 0.059 \\
\hline \multirow[t]{2}{*}{ Normal } & M & 8.33 & 16.67 & 16.67 & \\
\hline & $\mathrm{F}$ & 0 & 16.67 & 25.00 & \\
\hline \multirow[t]{2}{*}{ Overweight } & $M$ & 8.33 & 8.33 & 8.34 & \\
\hline & $\mathrm{F}$ & 41.67 & 41.67 & 16.67 & \\
\hline \multirow[t]{2}{*}{ Obese stage 1} & M & 8.33 & 0 & 0 & \\
\hline & $\mathrm{F}$ & 8.33 & 0 & 0 & \\
\hline \multirow[t]{2}{*}{ Obese stage 2} & M & 0 & 0 & 0 & \\
\hline & $\mathrm{F}$ & 16.67 & 0 & 0 & \\
\hline \multirow[t]{2}{*}{ Obese stage 3} & M & 0 & 0 & 0 & \\
\hline & $\mathrm{F}$ & 8.33 & 8.33 & 8.33 & \\
\hline \multirow[t]{2}{*}{ Opened eye balance time (sec) } & M & $44.08 \pm 17.20$ & $232.83 \pm 174.87$ & $95.67 \pm 50.00$ & 0.229 \\
\hline & $\mathrm{F}$ & $23.63 \pm 17.59$ & $26.21 \pm 30.89$ & $83.55 \pm 86.67$ & 0.137 \\
\hline \multirow[t]{2}{*}{ Closed eye balance time (sec) } & M & $16.47 \pm 7.51$ & $16.54 \pm 7.45$ & $35.62 \pm 17.33$ & 0.214 \\
\hline & $\mathrm{F}$ & $8.29 \pm 5.45$ & $7.48 \pm 5.26$ & $16.51 \pm 9.02$ & $0.022^{*}$ \\
\hline
\end{tabular}

Values are presented as mean \pm standard deviation.

${ }^{*} P<0.05$, significant difference. 
closed eye balance time of female compared to male bankers $(P<0.05)$. The males had more body water than the females $(60.03 \pm 4.57>47.50 \pm 2.25)$ while females had higher body fat percentage than males.

\section{DISCUSSION}

The present study investigated the physiological, anthropometric parameters, and balance skill responses of healthy bankers to FT. Our study showed significant positive effect of FT on all physiological and balance skill responses. This supports a recent finding that assessed BP response to incremental exercise testing and metaboreflex activation in treated-controlled hypertension, treated-uncontrolled hypertension, and untreated hypertension and control participants with normal blood pressure (Chant et al., 2018). The significant reduction in the blood pressures was pronounced in the females compared to male counterparts that could be associated with high proportion of the hypertensive female participants. Since most of the participants are middle-aged adults, our findings concord with the aging phenomena of women having higher prevalence of hypertension after menopause (age of 65 year) and men having higher prevalence at the fifth and sixth decade of life (Lionakis et al., 2012; Merz and Cheng, 2016). Ganesh and Deivanai Sundaram (2014) also reported prevalence of hypertension among bankers as revealed in our study where DBP of $83.36 \pm 5.61 \mathrm{mmHg}$ which a cardiovascular risk implication being reduced to $72.00 \pm 6.13 \mathrm{mmHg}$ at the end of the study.

According to Meruna and Dhanalakshmi (2012), the effect of short duration aerobic exercise on resting blood pressure and HR in prehypertensive and stage 1 hypertensive subjects found out that there was significant decrease in values of SBP, DBP, and HR after the 6 weeks of aerobic training in hypertensive individuals. The percentage change in the values were found to be more in men than women and changes was more marked in individuals below 50 years of age than individuals above 50 years due to aging. Research work has also reported higher HRs in males than female counterparts after submaximal exercise (Wheatley et al., 2014). Nonetheless, the higher HRs observed in the male participants has also been observed in previous research work (Quan et al., 2014).

Balance is the dynamic reactions of involuntary sensations and impulses that maintain an upright stance necessary for daily activities. The proper functioning of all active muscles in performing these activities. The goal of balance training is to improve balance through perturbation of the musculoskeletal system that will fa- cilitate neuromuscular capability, readiness and reaction. The higher skeletal muscle mass in the males explains the longer balance time in the males than the females and since balance is dependent on lightening, it goes to corroborate the lesser time of balance time recorded with the eyes closed seen in this study. Lorenz and Morrison (2015) have shown that FT has positive effect on balance skills which is in accordance with this study results. The increase in muscle mass in the female participants elevated the balance time recorded with the eyes closed. FT builds the neuromuscular capacity and agility (Lorenz and Morrison, 2015) as well as breath controls (Taylor, 2014) confirming the increased balance time this study.

The present study supports previous studies which showed that female bankers have higher total body fat percentage than their male counterparts (Carpenter et al., 2013; Gu et al., 2012; Kostrzewa-Nowak et al., 2015). This study corroborated the findings of Pasco et al. (2014) that increased age may be accompanied by increased per cent body fat, which invariably would lead to an increase in total body weight in middle aged persons. Chiu et al. (2017) suggested that fat tend to accumulate as one grows older because of decreased activity level and increased adipocytes in the body. Researches have shown the positive impact of FT on total body fat (Gutin et al., 2002; Kostrzewa-Nowak et al., 2015). FT also has a well-known role in preventing and reducing obesity, and has beneficial influence on insulin metabolism (Goran et al., 2000; Willis et al., 2012) however the reduction in the total body fat from the current results is not statistically significant. Hip circumference, it increased in the female bankers as the study progressed.

Studies have shown that abdominal adiposity decreases with FT and it is intensity dependent (Bergström et al., 2009; Russo, 2009) however decrease in the current study is statistically insignificant and could be attributed to the moderate intensity of the FT program the bankers engaged in. The female bankers tend to have higher hip circumference value than their male counterparts in this study which has been observed by some studies and was due to women having more peripheral distribution of fat in early adulthood and more limbs fat (Bacopoulou et al., 2015).

Short duration and moderate intensity resistance training in the study could be associated with the observation that, the effect of the FT on the skeletal muscle mass was statistically insignificant because FT especially resistance training induces muscle hypertrophy (Abe et al., 2003) however intensity, duration and type of FT is essential and these results suggest that all types of FT are equally beneficial for increasing endurance, balance, and traditional 
measures of strength. Studies have shown that most body water is contained inside of fat free mass and fat mass in the body. However, the fat cells contain the least body water compared to the rest of the tissues in the body (Yang et al., 2013). Water outside the cell is extra-cellular water (interstitial water and plasma water). Total body water is closely related to muscle mass; an estimate of lean body mass (of which the skeletal muscle mass has the highest percentage) can be easily if the total body water is actually measured. Total body water is remarkably constant; though the in a group of individuals of both sexes and all age varies from $40 \%$ to 70\% of the body weight (Yang et al., 2013). Males tend have higher total body water than the female counterparts and could be attributed to the fact that males have more lean mass than the female counterparts (Tuuri et al., 2005).

In this current study, the significant change in the BMI could be associated to the decrease in weight (Ingul et al., 2010) of the bankers. The current study results observed similar changes were pronounced in the female bankers which could be attributed to the fact that female participants at the start of the study and in general have higher body fat percentage than their counterparts (Kostrzewa-Nowak et al., 2015). The results showed that overweight is prevalent among bankers (Bonauto et al., 2014) could be associated with their sedentariness and stress from the banking job. The change in the waist-to-hip ratio could be traced to the decrement in the waist circumference which was more prevalent in the female bankers (Russo, 2009). Our study reaffirms earlier submission that FT have positive effect on weight (Russo, 2009).

The results of this study are in agreement that males in general have higher bone density than their counterparts due to the higher muscle mass than fat which is more in females (World Health Organization, 2008). Research has shown that FT prevent osteoporosis and increase bone density, size and both mechanical and tensile strength (Harding and Beck, 2017). FT programs that have been successful at increasing bone density have several Characteristics; training intensity above $70 \%$ one-repetition maximum which last for more than 12 months and training frequencies greater than twice a weak (Ochi et al., 2018). Therefore, the statistical insignificance of the effect of FT on the bone density could be attributed to the short duration and moderate intensity of resistance training in the study.

Authors concluded that FT had a positive effect on the physiological, anthropometric parameters, and balance skill profiles of healthy bankers. We recommend that policy making bodies in the banking sector should consider absorbing FT in decision-making policies. It would enable bankers to cultivate physically active lifestyles of stretching after sitting for some hours and short yoga (meditation) during the break periods. Bank management boards could employ exercise therapist so that they would attend to the hypokinetic needs of banking job.

\section{CONFLICT OF INTEREST}

No potential conflict of interest relevant to this article was reported.

\section{ACKNOWLEDGMENTS}

Authors express their sincere gratitude to all the participants, management and staff of Golden Bean hotel especially those at poolside and gym.

\section{REFERENCES}

Abe T, Kojima K, Kearns CF, Yohena H, Fukuda J. Whole body muscle hypertrophy from resistance training: distribution and total mass. Br J Sports Med 2003;37:543-545.

Addo PN, Nyarko KM, Sackey SO, Akweongo P, Sarfo B. Prevalence of obesity and overweight and associated factors among financial institution workers in Accra Metropolis, Ghana: a cross sectional study. BMC Res Notes 2015;8:599.

Bacopoulou F, Efthymiou V, Landis G, Rentoumis A, Chrousos GP. Waist circumference, waist-to-hip ratio and waist-to-height ratio reference percentiles for abdominal obesity among Greek adolescents. BMC Pediatr 2015;15:50.

Bergström I, Lombardo C, Brinck J. Physical training decreases waist circumference in postmenopausal borderline overweight women. Acta Obstet Gynecol Scand 2009;88:308-313.

Bonauto DK, Lu D, Fan ZJ. Obesity prevalence by occupation in Washington State, Behavioral Risk Factor Surveillance System. Prev Chronic Dis 2014;11:130219.

Carpenter CL, Yan E, Chen S, Hong K, Arechiga A, Kim WS, Deng M, Li Z, Heber D. Body fat and body-mass index among a multiethnic sample of college-age men and women. J Obes 2013;2013:790654.

Chant B, Bakali M, Hinton T, Burchell AE, Nightingale AK, Paton JFR, Hart EC. Antihypertensive treatment fails to control blood pressure during exercise. Hypertension 2018;72:102-109.

Chiu CH, Ko MC, Wu LS, Yeh DP, Kan NW, Lee PF, Hsieh JW, Tseng CY, Ho CC. Benefits of different intensity of aerobic exercise in modulating body composition among obese young adults: a pilot randomized controlled trial. Health Qual Life Outcomes 2017;15:168. 
Gallagher S, Heberger JR. Examining the interaction of force and repetition on musculoskeletal disorder risk: a systematic literature review. Hum Factors 2013;55:108-124.

Ganesh Kumar S, Deivanai Sundaram N. Prevalence and risk factors of hypertension among bank employees in urban Puducherry, India. Int J Occup Environ Med 2014;5:94-100.

Goran M, Fields DA, Hunter GR, Herd SL, Weinsier RL. Total body fat does not influence maximal aerobic capacity. Int J Obes Relat Metab Disord 2000;24:841-848.

Gu JK, Charles LE, Burchfiel CM, Fekedulegn D, Sarkisian K, Andrew ME, $\mathrm{Ma}$ C, Violanti JM. Long work hours and adiposity among police officers in a US northeast city. J Occup Environ Med 2012;54:1374-1381.

Gutin B, Barbeau P, Owens S, Lemmon CR, Bauman M, Allison J, Kang HS, Litaker MS. Effects of exercise intensity on cardiovascular fitness, total body composition, and visceral adiposity of obese adolescents. Am J Clin Nutr 2002;75:818-826.

Harding AT, Beck BR. Exercise, osteoporosis, and bone geometry. Sports (Basel) 2017;5(2)i:E29.

Hedén Stahl C, Novak M, Hansson PO, Lappas G, Wilhelmsen L, Rosengren A. Incidence of Type 2 diabetes among occupational classes in Sweden: a 35-year follow-up cohort study in middle-aged men. Diabet Med 2014;31:674-680.

Ingul CB, Tjonna AE, Stolen TO, Stoylen A, Wisloff U. Impaired cardiac function among obese adolescents: effect of aerobic interval training. Arch Pediatr Adolesc Med 2010;164:852-859.

Kostrzewa-Nowak D, Nowak R, Jastrzębski Z, Zarębska A, Bichowska M, Drobnik-Kozakiewicz I, Radzimiński Ł, Leońska-Duniec A, Ficek K, Cięszczyk P. Effect of 12-week-long aerobic training programme on body composition, aerobic capacity, complete blood count and blood lipid profile among young women. Biochem Med (Zagreb) 2015;25: 103-113.

Lionakis N, Mendrinos D, Sanidas E, Favatas G, Georgopoulou M. Hypertension in the elderly. World J Cardiol 2012;4:135-147.

Lorenz D, Morrison S. Current concepts in periodization of strength and conditioning for the sports physical therapist. Int J Sports Phys Ther 2015;10:734-747.

Meruna B, Dhanalakshmi V. Effect of short duration aerobic exercises on resting blood pressure and heart rate in pre-hypertensive and stage 1 hypertensive subjects. Indian J Physiother Occup Ther 2012;6:191-195.

Merz AA, Cheng S. Sex differences in cardiovascular ageing. Heart 2016; 102:825-831

Ochi E, Maruo M, Tsuchiya Y, Ishii N, Miura K, Sasaki K. Higher training frequency is important for gaining muscular strength under volumematched training. Front Physiol 2018;9:744.

Paoli A, Bianco A. What is fitness training? Definitions and implications: a systematic review article. Iran J Public Health 2015;44:602-614.

Pasco JA, Holloway KL, Dobbins AG, Kotowicz MA, Williams LJ, Brennan SL. Body mass index and measures of body fat for defining obesity and underweight: a cross-sectional, population-based study. BMC Obes 2014;1:9.

Quan HL, Blizzard CL, Sharman JE, Magnussen CG, Dwyer T, Raitakari $\mathrm{O}$, Cheung M, Venn AJ. Resting heart rate and the association of physical fitness with carotid artery stiffness. Am J Hypertens 2014;27:65-71.

Russo CR. The effects of exercise on bone. Basic concepts and implications for the prevention of fractures. Clin Cases Miner Bone Metab 2009;6:223-228

Sardarinia M, Akbarpour S, Lotfaliany M, Bagherzadeh-Khiabani F, Bozorgmanesh M, Sheikholeslami F, Azizi F, Hadaegh F. Risk factors for incidence of cardiovascular diseases and all-cause mortality in a middle Eastern population over a decade follow-up: tehran lipid and glucose study. PLoS One 2016;11:e0167623.

Seo MW, Jung HC, Song JK, Kim HB. Effect of 8 weeks of pre-season training on body composition, physical fitness, anaerobic capacity, and isokinetic muscle strength in male and female collegiate taekwondo athletes. J Exerc Rehabil 2015;11:101-107.

Taylor D. Physical activity is medicine for older adults. Postgrad Med J 2014;90:26-32.

Tuuri G, Keenan MJ, West KM, Delany JP, Loftin JM. Body water indices as markers of aging in male masters swimmers. J Sports Sci Med 2005;4:406-414

Wheatley CM, Snyder EM, Johnson BD, Olson TP. Sex differences in cardiovascular function during submaximal exercise in humans. Springerplus 2014;3:445.

Whelton SP, Chin A, Xin X, He J. Effect of aerobic exercise on blood pressure: a meta-analysis of randomized, controlled trials. Ann Intern Med 2002:136:493-503.

Willis LH, Slentz CA, Bateman LA, Shields AT, Piner LW, Bales CW, Houmard JA, Kraus WE. Effects of aerobic and/or resistance training on body mass and fat mass in overweight or obese adults. J Appl Physiol (1985) 2012;113:1831-1837.

World Health Organization. Waist circumference and waist-hip ratio: report of a WHO expert consultation. Geneva (Switzerland): World Health Organization; 2008.

Yang Y, Smith DL Jr, Hu HH, Zhai G, Nagy TR. Chemical-shift water-fat MRI of white adipose depots: inability to resolve cell size differences. Int J Body Compos Res 2013;11:9-16.

Zhu X, Haegele JA. Gender- and school-level correlates of growth in health-related fitness knowledge among US high-school students. Health Educ J 2018;77:927-938. 